\title{
Experimental and numerical evaluation of composite repairs on wood beams damaged by cross-graining
}

\author{
R.D.S.G. Campilho, M.F.S.F. de Moura, A.M.J.P. Barreto, J.J.L. Morais, J.J.M.S. Domingues
}

A B S T R A C T

An experimental and Finite Element study was performed on the bending behaviour of wood beams of the Pinus Pinaster species repaired with adhesively-bonded carbon-epoxy patches, after sustaining damage by cross-grain failure. This damage is characterized by crack growth at a small angle to the beams longitudinal axis, due to misalignment between the wood fibres and the beam axis. Cross-grain failure can occur in large-scale in a wood member when trees that have grown spirally or with a pronounced taper are cut for lumber. Three patch lengths were tested. The simulations include the possibility of cohesive fracture of the adhesive layer, failure within the wood beam in two propagation planes and patch interlaminar failure, by the use of cohesive zone modelling. The respective cohesive properties were estimated either by an inverse method or from the literature. The comparison with the tests allowed the validation of the proposed methodology, opening a good perspective for the reduction of costs in the design stages of these repairs due to extensive experimentation.

Keywords:

Wood

Composite

Repair

Cohesive zone models

Finite element analysis

\section{Introduction}

Wood is amongst the oldest construction materials in the world and has been widely used to build large-scale structures like bridges, railroad infrastructures, lightweight warehouses and residential buildings $[1,2]$. This natural and renewable material is characterized by high strengths under parallel to grain tension and compressive loads, which are nearly unique as specific properties (i.e., divided by its weight). Moreover, it performs well under the influence of wind and especially earthquake loads, due to the low stiffness of wood, especially in the direction perpendicular to fibres, providing a redistribution of loads in the structure [3-7]. However, without proper maintenance, wood deteriorates due to fungi and insects, and swelling and shrinkage caused by variations on ambient humidity. Poor initial design or construction, or short duration episodes such as overloads and earthquakes, can also be pointed out as origins of damage [8]. Some studies were published in the last decades about the reinforcement [9] and repair [2,6] of wood structures with aluminium/steel and composites. In recent years, composite materials, which are already extensively used in several high performance applications in the aerospace, automo- tive, marine and military industries (Carbon-Fibre Reinforced Plastics; CFRP), and in house-hold and leisure appliances (Glass-Fibre Reinforced Plastics; GFRP), are gaining acceptance for structural strengthening and repair. In fact, composites offer a set of benefits over conventional engineering materials, such as higher strength and lighter weight than conventional materials, availability in the form of thin pultruded elements of different shapes (e.g. Sika ${ }^{\circledR}$ CarboDur strips) with continuously decreasing costs, corrosion resistance and flexibility. Transversely to these issues, wood is tolerant to large strains before failure, necessary to develop the characteristic high strength of composite materials [9]. The study of wood structures reinforced with composites dates back to the 1980 s and has been under research since then [5,10-15]. The work of Borri et al. [5] is a comprehensive experimental and numerical study on the reinforcement of wood beams with unidirectional CFRP laminates and pultruded bars. The four-point bending (4 PB) test was used to evaluate the effectiveness of the proposed methods. Reinforcing with CFRP sheets in the tension face significantly increased the bending characteristics of the beams (three sheets of CFRP resulted on a 60\% increase of the flexural strength). Results were not so impressive with CFRP bars, with the sole advantage of this technique being related to its aesthetics, since the bars are not visible. Regardless of the reinforcement method, failure always occurred within the wood beams, with an adhesion failure between the reinforcement and the wood taking place only afterwards. Oppositely to the reinforcement studies, not many 
works were carried out in recent years on the repair of wood structures with composites, and the ones available are limited to experimental analyses. Moreover, most of the proposed techniques are not specifically suited to in situ application and require the damaged members dismantlement, making them less appealing [2]. On the other hand, it is unrealistic to apply available empirical results for the repair of timber structures, since much of the research is based upon timber reinforcement rather than repair [16,17]. The available techniques involve adding a bolted or fastened member in parallel, stitch bolting, inserting steel or fibreglass dowels, epoxy filling approaches, bonding of thin composite plates on the beam exposed faces and wrapping of the beams with composites at the damaged region [18]. Radford et al. [2] proposed a repair methodology for slender wood beams damaged by a longitudinal crack along their length. Steel nails or GFRP pultruded rods were adhesively-bonded through the beams thickness. The suitability of this technique was checked with scaled tests, being the number of rods and respective loci the investigated parameters. The GFRP rods were found to be more effective than the steel ones in restoring the stiffness and strength of the undamaged beams. The works of Lopez-Anido et al. $[19,20]$ describe a repair technique for decayed underwater wood piles. The proposed method consists on the application of a composite shield around the wood pile to enclose its deteriorated portion. Following, the region in-between is filled with a grouting material to transmit the pile loads to the shield. The feasibility of the proposed repair methodology was demonstrated with artificially damaged full-size specimens. Results showed that the full recovery of the piles undamaged strength can be achieved with this technique.

In this work, an experimental and numerical study was performed on the repair of wood beams of the Pinus Pinaster species with adhesively-bonded patches, after sustaining damage by cross-grain failure. This mechanism is characterized by a tensile fracture at a small angle to the beams longitudinal axis, due to a small misalignment between the wood fibres and the beam axis $[2,21]$. This can occur in large-scale in a wood member when trees that have grown spirally or with a pronounced taper are cut for lumber. Cross-graining drastically reduces the tensile strength of wood, typically leading to abrupt and early bending failures [2224]. Three patch lengths $\left(L_{P}\right)$ were tested under $4 \mathrm{~PB}$. The proposed Finite Element (FE) methodology aims the reduction of time and cost associated to extensive experimentation, otherwise necessary for the widespread use of these repairs, since no accurate predictive tools are yet available to the designer for adhesively-bonded wood repairs. The FE simulations include the possibility of cohesive fracture of the adhesive layer, failure within the wood beam through different propagation planes and interlaminar failure of the patch. Cohesive zone models (CZM's) were employed to simulate these fractures, whose properties were estimated either by an inverse method or from literature data.

\section{Cohesive zone model}

\subsection{Model description}

A mixed-mode (I + II) CZM implemented within interface finite elements was used to simulate an adhesive layer of Araldite ${ }^{\circledR} 2015$ with thickness $\left(t_{A}\right)$ of $0.2 \mathrm{~mm}$. A trapezoidal law between stresses $(\sigma)$ and relative displacements $\left(\delta_{r}\right)$ between homologous points of the interface elements with zero thickness was considered (Fig. 1), to account for the adhesive ductility [25-27]. The homologous points correspond to the initially superimposed points of the interface elements in the numerical model, which are connected by the mixed-mode CZM of Fig. 1. The trapezoidal law was also used with some modifications to simulate the wood and patch fractures.

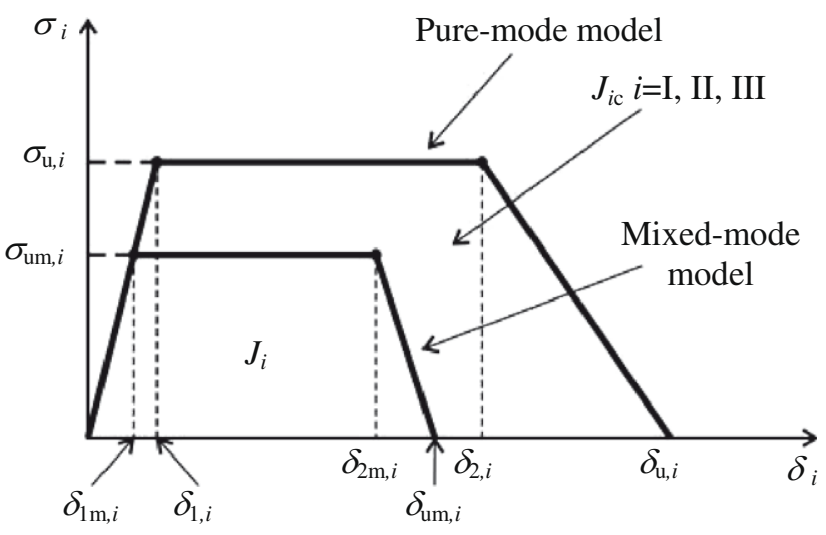

Fig. 1. The trapezoidal softening law for pure-mode and mixed-mode.

The formulation allows a mixed-mode behaviour, in which damage onset is predicted using the quadratic stress criterion:

$$
\begin{array}{ll}
\left(\frac{\sigma_{\mathrm{I}}}{\sigma_{\mathrm{u}, \mathrm{I}}}\right)^{2}+\left(\frac{\sigma_{\mathrm{II}}}{\sigma_{\mathrm{u}, \mathrm{II}}}\right)^{2}=1 & \text { if } \sigma_{\mathrm{I}}>0, \\
\sigma_{\mathrm{II}}=\sigma_{\mathrm{u}, \mathrm{II}} & \text { if } \sigma_{\mathrm{I}} \leqslant 0,
\end{array}
$$

where $\sigma_{i}(i=\mathrm{I}, \mathrm{II})$ represents the current stress in each mode and $\sigma_{\mathrm{u}, i}$ ( $i=\mathrm{I}, \mathrm{II})$ the corresponding local strength. The first Eq. (1) can be rewritten as a function of the relative displacements:

$\left(\frac{\delta_{1 \mathrm{~m}, \mathrm{I}}}{\delta_{1, \mathrm{I}}}\right)^{2}+\left(\frac{\delta_{1 \mathrm{~m}, \mathrm{II}}}{\delta_{1, \mathrm{II}}}\right)^{2}=1$.

$\delta_{1, i}(i=\mathrm{I}, \mathrm{II})$ are the pure-mode relative displacements at damage initiation and $\delta_{1 \mathrm{~m}, i}(i=\mathrm{I}, \mathrm{II})$ the corresponding mixed-mode ones. Stress softening onset was predicted using a criterion similar to (2)

$\left(\frac{\delta_{2 \mathrm{~m}, \mathrm{I}}}{\delta_{2, \mathrm{I}}}\right)^{2}+\left(\frac{\delta_{2 \mathrm{~m}, \mathrm{II}}}{\delta_{2, \mathrm{II}}}\right)^{2}=1$.

$\delta_{2, i}(i=\mathrm{I}, \mathrm{II})$ are the relative displacements in pure-mode at stress softening onset and $\delta_{2 \mathrm{~m}, i}(i=\mathrm{I}, \mathrm{II})$ the corresponding mixed-mode ones. Crack growth was simulated by the linear energetic criterion

$\frac{J_{\mathrm{I}}}{J_{\text {Ic }}}+\frac{J_{\text {II }}}{J_{\text {IIc }}}=1$.

$J_{i c}(i=\mathrm{I}, \mathrm{II})$ is the fracture energy in the respective pure mode. When the equality of Eq. (4) is achieved at a given integration point damage grows and stresses are released, with the exception of normal compressive ones. A detailed description of this model can be found in the work of Campilho et al. [28].

\subsection{Cohesive parameters}

The presented mixed-mode CZM was used to simulate a $t_{A}=0.2$ mm layer of Araldite ${ }^{\circledR} 2015$. The adhesive layer elastic stiffness in tension and shear (up to $\delta_{1, i}$, Fig. 1 ) is defined from the experimentally measured values of Young's modulus $(E=1850 \mathrm{MPa})$ and shear modulus ( $G=650 \mathrm{MPa}$ ) [29], as detailed in the work of Campilho et al. [28]. In the present work, the cohesive laws of the adhesive layer in pure modes I and II were estimated by Double Cantilever Beam (DCB) (mode I) and End-Notched Flexure (ENF) (mode II) tests using an inverse data fitting procedure [30-32]. This course of action is supported by the typically varying mechanical properties of adhesive layers with $t_{A}$, diverging also to the adhesive bulk properties [25]. This is due to the influence of the surrounding adherends on the height and extension of the Fracture Process Zone (FPZ). Actually, in adhesive layers, the FPZ height is naturally confined by $t_{A}$, but its length extends much longer ahead of the 
crack tip than in bulk adhesives. [25-27]. Failure within the wood (Fig. 2) in the RL plane (horizontal longitudinal plane of the beam) and in the $L R$ plane (cross-sectional plane of the beam) is also considered in the FE models, to simulate the experimental fracture events. The cohesive parameters for an $R L$ fracture were established from previous works [33,34]. The $L R$ parameters were estimated from typical values for this wood species. For the wood and patch cohesive laws, triangular laws were considered $\left(\delta_{2, i}=\delta_{1, i}\right.$ in Fig. 1$)$, due to the absence of plasticity in these materials, and a penalty function method was used until $\sigma_{\mathrm{u}, i}$ (Fig. 1). Table 1 details the cohesive parameters for the different fractures [33-35].

\section{Experimental work}

Fig. 2 specifies the geometry and test setup of the repairs. The analysis also comprises the undamaged and unrepaired (cracked) beams, for an optimization study. The proposed repair consists on adhesively-bonding a CFRP patch in the face under tension to strengthen the cracked region of the beam. The characteristic dimensions are the beam length $(a=300 \mathrm{~mm})$, width $(b=20 \mathrm{~mm})$ and height ( $h=20 \mathrm{~mm}$ ), crack length projection along the $L$ direction $\left(L_{C^{\prime}}=20 \mathrm{~mm}\right)$, cross-grain angle $\left(\alpha_{c}=15^{\circ}\right)$, patch thickness $\left(t_{H}=0.6 \mathrm{~mm}\right), t_{A}=0.2 \mathrm{~mm}$, and $L_{P}=40,60$ and $80 \mathrm{~mm}$. It should be emphasized that scaled repair geometries of small dimensions were used to provide design principles for the proposed repair solution and to validate the proposed numerical methodology. It is not guaranteed that the scaled specimens strength is in exact proportion to the dimensions of an identical largescale repair, especially due to a typical larger number of defects in large-scale wood trunks, scale effects in layered composite materials [36], and also accounting for the different behaviour of adhesive layers depending on their thickness constraints [37]. The 4 PB test setup assures a constant bending moment at the repaired central region of the beam $\left(S=260 \mathrm{~mm}, S^{\prime}=130 \mathrm{~mm}, d_{c}=10 \mathrm{~mm}, e=20 \mathrm{~mm}\right)$. $\boldsymbol{A}$ and $\boldsymbol{B}$ represent the supporting and loading cylinders, respectively. Since the patch will experience uniaxial tension, it consists on a unidirectional lay-up with the fibres aligned along the beam length [38]. The axes 1-3 of Fig. 2 correspond to the fibre, transverse and thickness directions of the CFRP patch, respectively. The $R, L, T$ coordinate system pertains to the wood orientations (fibres longitudinal direction $(L)$, rings radial direction $(R)$ and rings tangential direction $(T)$ ). Conditioning of the wood beams prior to fabrication of the repairs and testing consisted on leaving the wood specimens in a dry environment for at least 1 month, to be completely consistent with the characterization of elastic properties performed in references [33,34]. Considering the specimens fabrication, particular attention should be paid to the crossgrain crack. A vertical saw equipment with a $1 \mathrm{~mm}$ thickness High-Speed Steel saw was used to this end, yielding an approximately $1 \mathrm{~mm}$ gap between the crack faces, which was also considered in the FE simulations. For a precise cut a guiding system was used, comprising a ruler parallel to the saw and a $15^{\circ}$ wedge. A sharp crack tip was afterwards produced with a $0.1 \mathrm{~mm}$ thickness razor blade. This blade, which was initially centred in the $1 \mathrm{~mm}$ crack gap using calibrated steel bars, was used to extend the crack up to the value of $L_{G}$, measured with a digital calliper. The patches were fabricated using CFRP prepreg (Texipreg HS 160 RM from SEAL ${ }^{\circledR}$ ) with $0.15 \mathrm{~mm}$ of ply thickness. The value of $t_{H}$ was selected numerically before the experiments as the minimum value not to exceed the CFRP strength in the fibres direction. The wood and patch surfaces to be bonded were previously abraded and cleaned with compressed air (wood) or acetone (CFRP patch). The ductile adhesive Araldite ${ }^{\circledR} 2015$ was used to bond the patches, being employed $0.2 \mathrm{~mm}$ diameter nylon fishing lines as stoppers near the patch edges to produce the desired value of $t_{A}$, and a manual patch positioning method with a digital calliper for a correct alignment. The specimens were cured at room temperature. The tests were carried
Table 1

Cohesive parameters in pure modes I and II used to simulate different failures.

\begin{tabular}{llclll}
\hline Cohesive laws & & $J_{\text {ic }}(\mathrm{N} / \mathrm{mm})$ & $\sigma_{\mathrm{U}, i}(\mathrm{MPa})$ & $\delta_{2, i}(\mathrm{~mm})$ & $\delta_{\mathrm{U}, i}(\mathrm{~mm})$ \\
\hline Adhesive layer & I & 0.43 & 23.0 & 0.0187 & 0.021 \\
& II & 4.70 & 22.8 & 0.1710 & 0.248 \\
CFRP interlaminar & I & 0.33 & 25.0 & $2.5 \times 10^{-5}$ & 0.026 \\
& II & 0.79 & 13.5 & $1.4 \times 10^{-5}$ & 0.117 \\
Wood in the $R L$ plane & I & 0.2 & 16 & $1.6 \times 10^{-5}$ & 0.025 \\
& II & 1.2 & 16 & $1.6 \times 10^{-5}$ & 0.150 \\
Wood in the $L R$ plane & I & 25 & 65 & $6.5 \times 10^{-5}$ & 0.77 \\
& II & 1.2 & 16 & $1.6 \times 10^{-5}$ & 0.15 \\
\hline
\end{tabular}

out in an Instron ${ }^{\circledR} 1125$ testing machine with a $100 \mathrm{kN}$ load cell, at room temperature and under displacement control $(2 \mathrm{~mm} / \mathrm{min})$. The values of load $(P)$ and loading cylinders displacement $(\delta)$ were recorded at a sampling rate of five points per second. From the 10 specimens tested for each condition, at least seven valid results were always obtained.

\section{Numerical analysis}

The FE simulations were performed in ABAQUS $^{\circledR}$, considering geometrical non-linearities. The wood and CFRP patches were modelled as elastic orthotropic materials, with the following properties: $\operatorname{wood}\left(E_{L}=10.2 \mathrm{GPa}, E_{R}=E_{T}=1010 \mathrm{MPa}, v_{L R}=v_{L T}=0.342\right.$, $v_{R T}=0.380, G_{L R}=1120 \mathrm{MPa}, G_{L T}=1040 \mathrm{MPa}, G_{R T}=170 \mathrm{MPa}$; $[33,34])$ and CFRP $\left(E_{1}=109 \mathrm{GPa}, E_{2}=E_{3}=8819 \mathrm{MPa}, v_{12}=v_{13}=\right.$ $0.342, v_{23}=0.380, G_{12}=G_{13}=4315 \mathrm{MPa}, G_{23}=3200 \mathrm{MPa}$ [39]). These properties were obtained either performing specific tests or taking advantage of the available relations for orthotropic elasticity. More specifically, the most important properties for the outcome of the simulations (such as $E_{L}$ and $v_{L R}$ for the wood beam or $E_{1}$ and $v_{12}$ for the CFRP patch) were always obtained from experimental tests. Apart from this fact, and since there is a significant stiffness variation of wood between specimens of the same species, the reference value of $E_{L}$ had to be tuned to the experimental $P-\delta$ curves, giving $10.2 \mathrm{GPa}$ as the value that most accurately represented the experiments. The FE mesh was built with plane-stress 8 -node rectangular and 6-node triangular solid elements. Fig. 3 relates to the $L_{P}=40 \mathrm{~mm}$ repair (a) and respective detail at the damaged region (b). Near the cylinders, 60 elements were employed over a length of $4 \mathrm{~mm}$ for a smooth sliding under load. In the repairs height, two mesh sizes were applied: a more refined mesh at the tensile region comprising the cross-grain crack, with 22 elements, and a coarser mesh with ten elements at the compression region. In the beams length, the mesh is moderately refined along the extent of the crack, since this region is not expected to be severely loaded. The bonded regions at both sides of the crack were simulated with forty elements, with bias effects for an accurate (a)

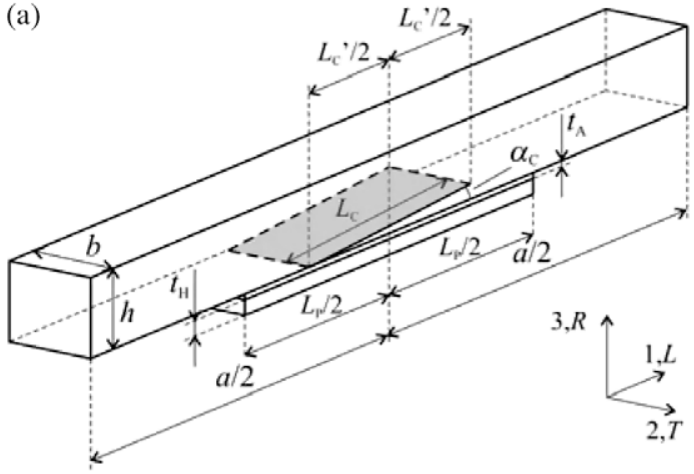

(b)

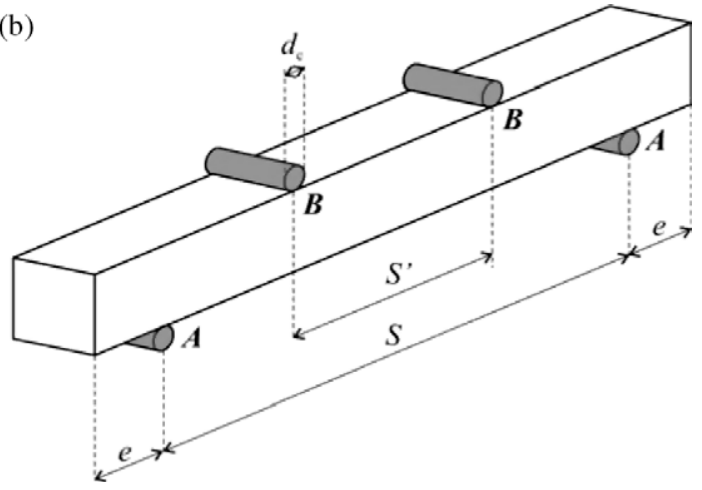

Fig. 2. Schematic representation of the repair with the characteristic dimensions (a) and test setup (b). 
(a)

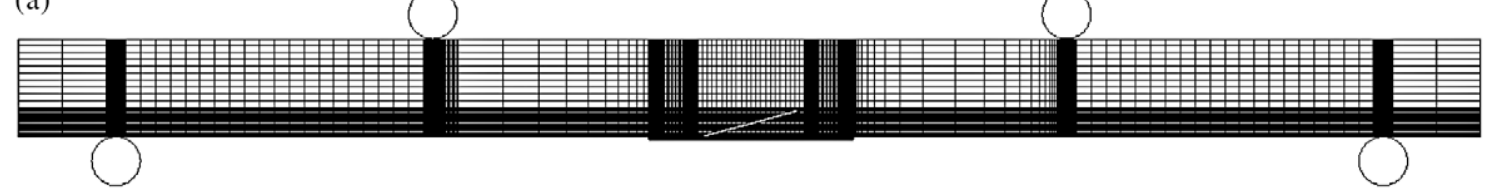

(b)

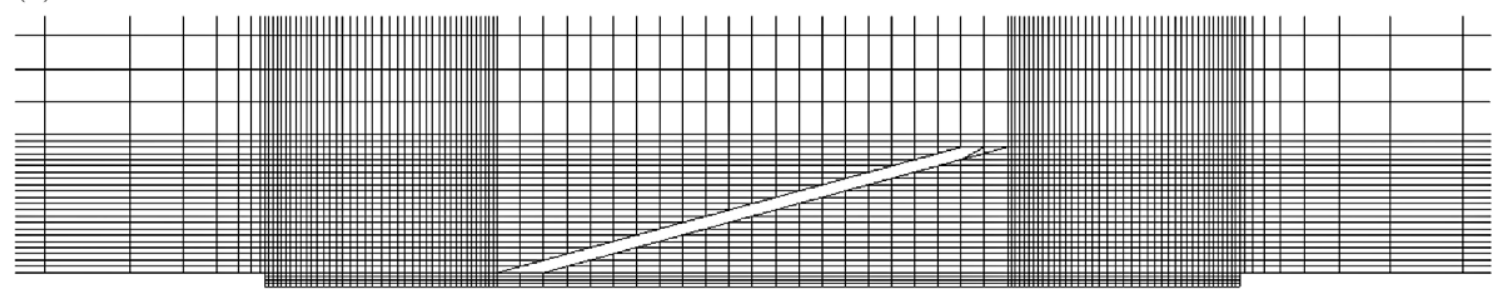

Fig. 3. Mesh for the $L_{P}=40 \mathrm{~mm}$ repair (a) and detail at the repaired region (b).

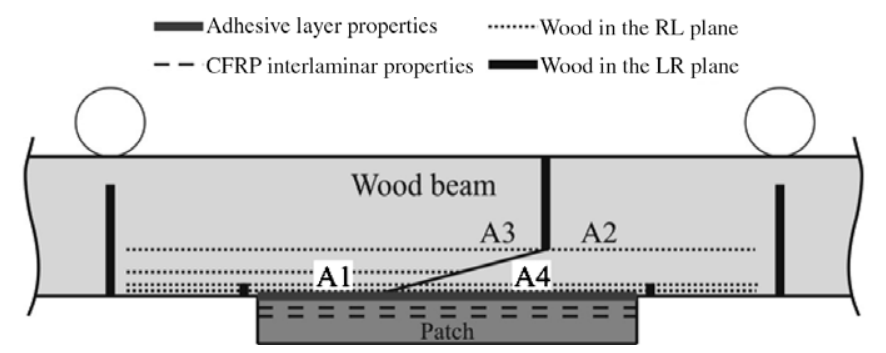

Fig. 4. Placement of the interface elements with different cohesive laws in the numerical models.

characterization of the expected peak stresses near the patch edges $[39,40]$. The patch was modelled with four solid elements through thickness. Fig. 4 shows the cohesive elements loci to simulate different fractures. The adhesive layer was simulated with the trapezoidal cohesive laws. The possibility of a patch interlaminar failure was equated at 0.15 and $0.30 \mathrm{~mm}$ of the adhesive/patch interface. Within the wood beam, the mesh was set to include cohesive elements horizontally to simulate $R L$ failures. The experiments allowed the establishment of the limit distances between these planes and the adhesive/patch interface, defined at 0.3 and $0.6 \mathrm{~mm}$. In Fig. 4, failure paths A1 and A4 correspond to damage propagation near the smaller and larger bonds, respectively, either in the patch, adhesive or wood beam. $R L$ damage propagations were also considered initiating at the crack tip and growing up to the rightmost (path A2) and leftmost (path A3) loading cylinder, and initiating at the middle of the cross-grain crack height up to the leftmost loading cylinder. $L R$ failures were equated below the loading cylinders and initiating at the crack tip. The propagation of the cross-grain crack with its initial orientation was not addressed, since this would pertain to a very specific set of conditions that are not satisfied in most fabricated repairs. In fact, these present the wood fibres almost perfectly aligned in the $L$ direction and, under these conditions, the induced cross-grain crack is expected to propagate either in the $R L$ or $L R$ planes.

\section{Results}

\subsection{Numerical}

Evaluation of the repairs initiates with an elastic stress analysis in the adhesive layer, considering through-thickness normal stresses $(\sigma$; Fig. 5) and shear stresses in the $R L$ plane of the beam $(\tau$; Fig. 6). The main tendencies reported in this study can be extended to the neighbouring horizontal planes in the patch and wood,

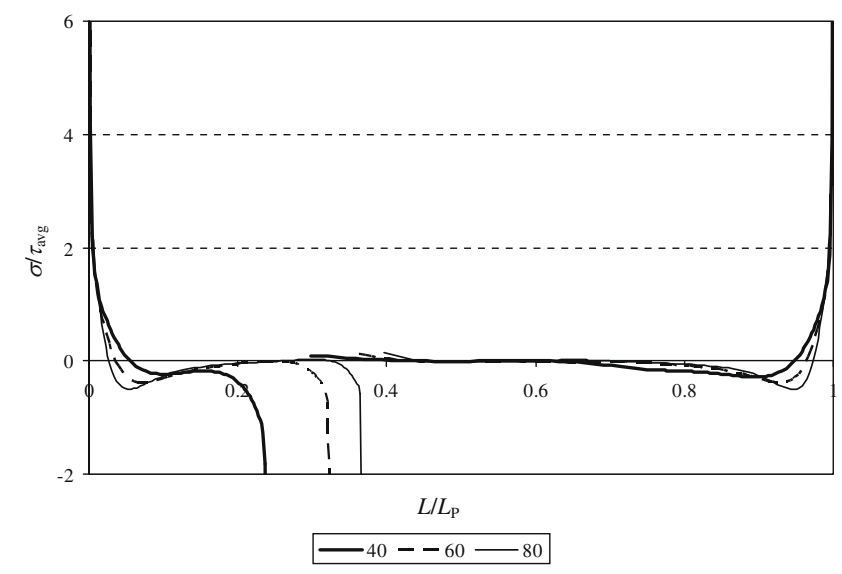

Fig. 5. Normalized $\sigma$ stress distributions in the adhesive layer as a function of $L_{P}$.

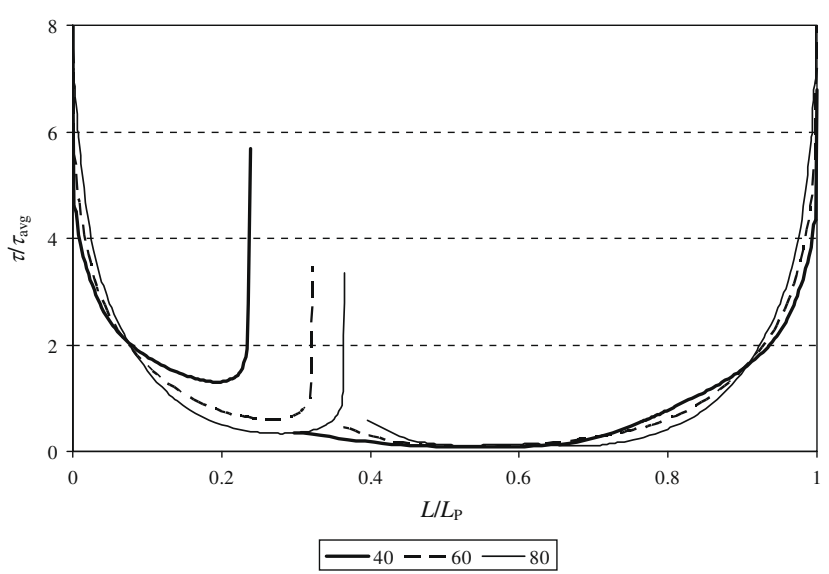

Fig. 6. Normalized $\tau$ stress distributions in the adhesive layer as a function of $L_{P}$.

despite some expected variations in the peak values [41]. $\sigma$ and $\tau$ stresses are normalized by $\tau_{\text {avg, }}$, the average shear stress along $L_{P}$ for each one of the repairs. $L / L_{P}$ represents the patch normalized distance from the patch edge. $\sigma$ stresses are approximately nil, excluding at the patch edges, where $\sigma$ peel stresses peak, and at the crack gap, which shows a compressive singularity. $\sigma$ stresses are usually significantly smaller in magnitude than $\tau$ stresses along the bond length. $\tau$ stresses peak near the patch edges, gradually increasing up to those regions. The bond regions outside the wood spike (approximately $0<L / L_{P}<0.25$ and $0.75<L / L_{P}<1$ ) assure the 
load transfer at the tension regions, leaving the weakened wood spike region practically unloaded. With the increase of $L_{P}, \sigma$ compressive stresses diminish at the bond gap and increase near the patch edges. The smallest value of $L_{P}$ yields significantly higher magnitude $\tau$ stresses at the smaller bond overloading this region, which may cause a premature failure. Increasing $L_{P}$ gradually cancels this effect, as $\tau$ stresses level between the two bonds. This analysis points to an increase of the maximum load $\left(P_{m}\right)$ with $L_{P}$, based on the increase of the shear area available to deviate loads from the cracked region to the sane portions of the beam, and due to the levelling of $\tau$ stresses between the two bonds.

The numerical fractures, which revealed to be consistent with the test results presented in the following section, are also characterized. The undamaged beams showed a $L R$ pure tension fracture below the loading cylinders. Damage in the unrepaired beam initiated at the tip of the cross-grain crack, growing horizontally as an $R L$ fracture along path A2 (event UNR1). This led to a small drop of $P$, which then continued to increase as the $R L$ crack propagated. $P_{m}$ occurred after this crack approached the loading cylinder, by instantaneous failure at path A3 (event UNR2; Fig. 7a). Final fracture for the unrepaired beam, and also for the subsequent repairs, occurred by a vertical $L R$ failure initiating at the cross-graining crack tip (event UNR3). Since this fracture occurred subsequently to $P_{m}$ and at a very reduced value of $P$, it will be omitted in the following numerical and experimental fracture descriptions. The FE simulation of the $L_{P}=40 \mathrm{~mm}$ repair (Fig. $7 \mathrm{~b}$ and c) showed a linear behaviour up to $P_{m}$ (event LP1), occurring due to simultaneous $R L$ failures in the wood at path $\mathrm{A} 1$ at $0.3 \mathrm{~mm}$ of the adhesive layer and at path A2. At this instant, $P_{m}$ dropped abruptly while the crack at path A2 continued to grow. Fracture at path A1 is related to the smaller length of this bond, causing higher stresses than at the opposite bond (Figs. 5 and 6). This is more evident for the smallest value of $L_{P}$. Subsequently, the repair failed abruptly at path A3 (event LP2). It must be mentioned that, at the time of the initial wood failure at path A1, most of the adhesive layer cohesive elements were already in the softening stage $\left(\delta_{i}>\delta_{1 \mathrm{~m}, i}\right.$ in Fig. 1$)$, implying that small variations in the repair constituents properties could result on a cohesive failure of the adhesive layer. The $L_{P}=60$ and $80 \mathrm{~mm}$ (Fig. 7d) repairs failed concurrently at paths A1 (in the wood at $0.3 \mathrm{~mm}$ of the adhesive layer), A2 and A3.

\subsection{Experimental}

The experimental damage events are described in this section. The undamaged wood beam attained experimentally $P_{m}$ by a pure tension $L R$ fracture below the loading cylinders (Fig. 8a). $R L$ crack propagation followed under residual loads. For the unrepaired beams, damage initiated by a $R L$ propagation along path $\mathrm{A} 2$ (event UNR1), causing only a reduction of stiffness. Damage continued to grow steadily up to $P_{m}$, occurring due to $R L$ fractures at paths A2 and A3 (Fig. 8b), instantaneously up to near the loading cylinders (event UNR2). In the $L_{P}=40 \mathrm{~mm}$ repairs, damage initiated with simultaneous $R L$ failures at paths $\mathrm{A} 1$ (in the wood at $0.3 \mathrm{~mm}$ of the adhesive layer) and A2, causing a drop of $P_{m}$ (event LP1). After-
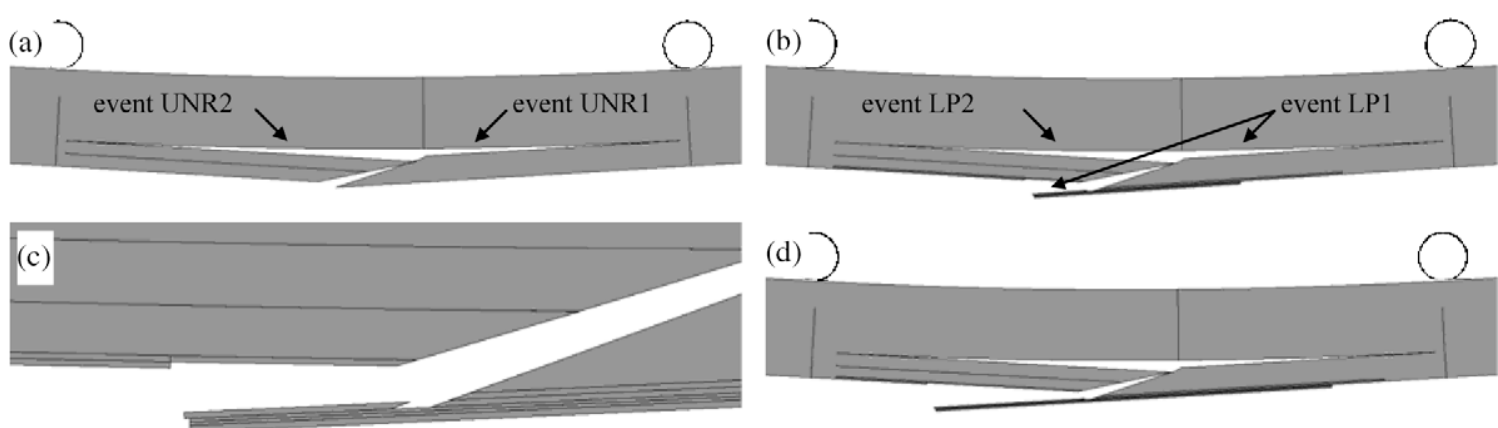

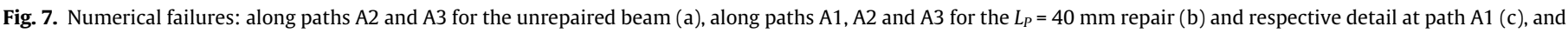
along paths $\mathrm{A} 1, \mathrm{~A} 2$ and $\mathrm{A} 3$ for the $L_{P}=80 \mathrm{~mm}$ repair (d).
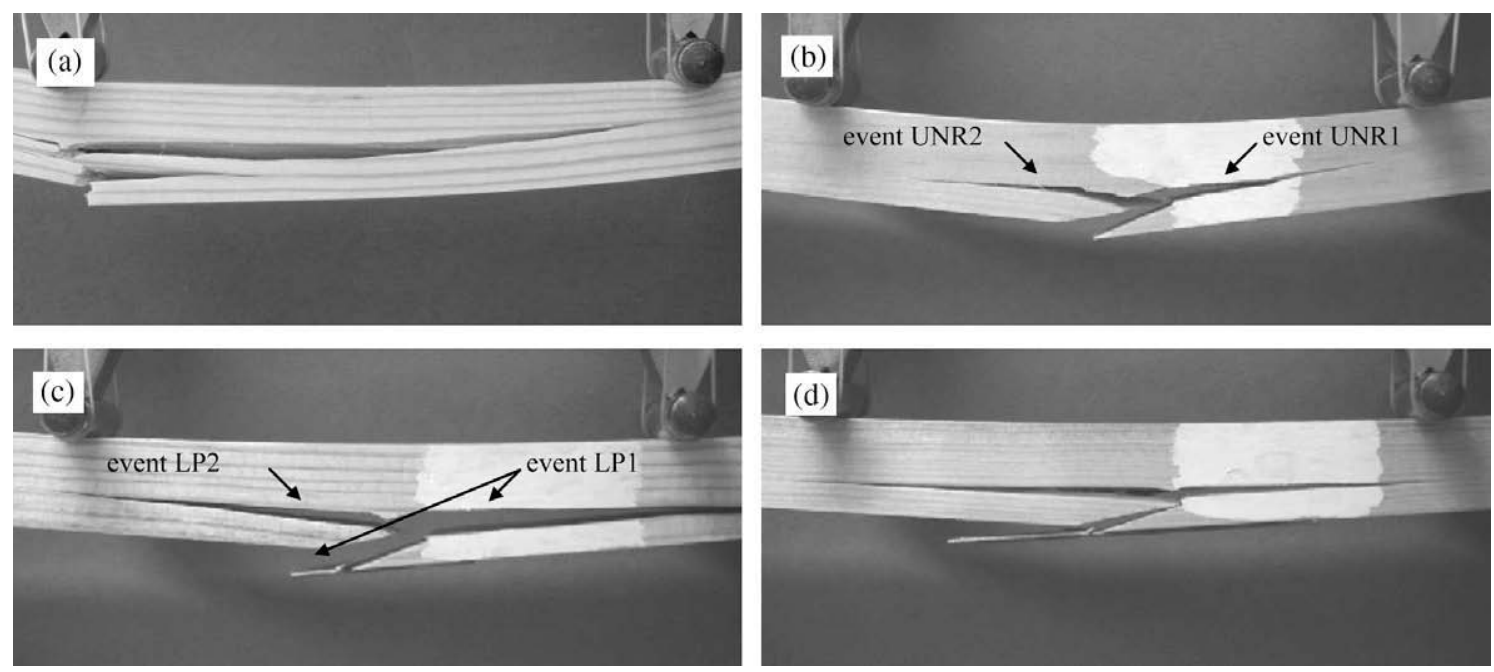

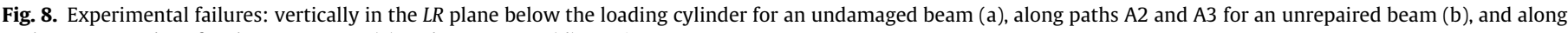
paths $\mathrm{A} 1, \mathrm{~A} 2$ and $\mathrm{A} 3$ for the $L_{P}=40 \mathrm{~mm}$ (c) and $L_{P}=80 \mathrm{~mm}$ (d) repairs. 
wards, a $R L$ failure at path A3 occurred (event LP2; Fig. 8c). The observed fracture at path $\mathrm{A} 1$ within the wood beam denotes a weaker strength compared to the adhesive layer and respective interfaces. Failure in the $L_{P}=60$ and $80 \mathrm{~mm}$ (Fig. 8d) repairs occurred simultaneous at paths $A 1$ (in the wood at $0.3 \mathrm{~mm}$ of the adhesive layer), A2 and A3. Up to $P_{m}$, no evidence of damage was found. Fracture at paths $A 1, A 2$ and $A 3$ always occurred concurrently, owing to the bigger values of $P_{m}$ than for the previous repair, caused by a larger shear resistant area.

\subsection{Experimental/numerical comparison}

Figs. 9 and 10 compare the experimental and numerical $P-\delta$ curves for two of the tested conditions. The unrepaired beam (Fig. 9) revealed numerically a drop of $P$ owing to damage initiation at the tip of the cross-graining crack, which is clearly visible at $\delta \approx 1.8 \mathrm{~mm}$ and is within the range of the experiments (event UNR1). The numerical value of $P_{m}$, caused by an abrupt $R L$ failure at path A3 (event UNR2), overpredicted the experiments for most of the specimens. After the drop of $P_{m}, P$ increased up to complete failure, by tension above the cross-grain crack tip (event UNR3). Fig. 10, representing the $L_{P}=40 \mathrm{~mm}$ repair, displays a nearly linear numerical $P-\delta$ curve up to $P_{m}$ (event LP1; $\delta \approx 4 \mathrm{~mm}$ ), which agreed with the average of the experiments. As already discussed, the value of $P_{m}$ is related to simultaneous $R L$ failures in the wood beam at paths $A 1$ and $A 2$. The repair still sustained loads up to fracture at path A3 (event LP2).

Figs. 11 and 12 evaluate the experimental and FE results, in terms of elastic stiffness $(K)$ and $P_{m}$, respectively, as functions of

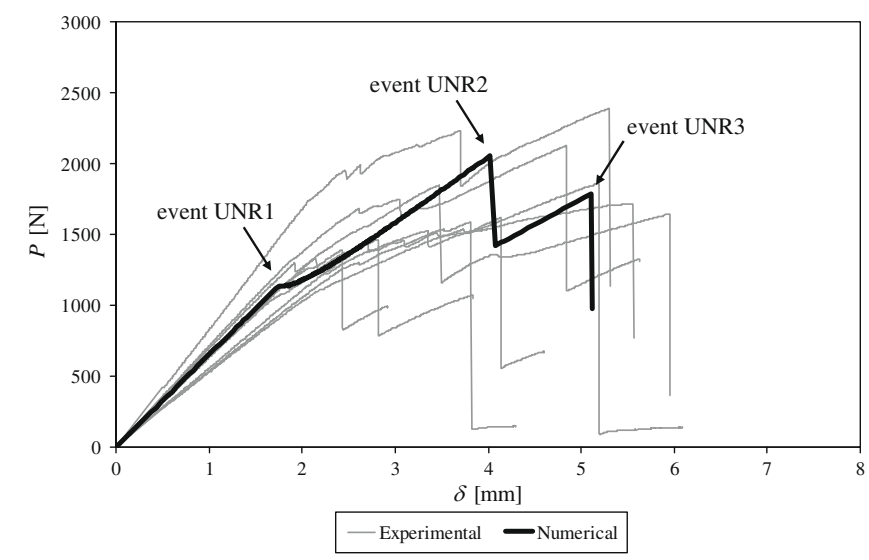

Fig. 9. Experimental and numerical $P-\delta$ curves for the unrepaired beam.

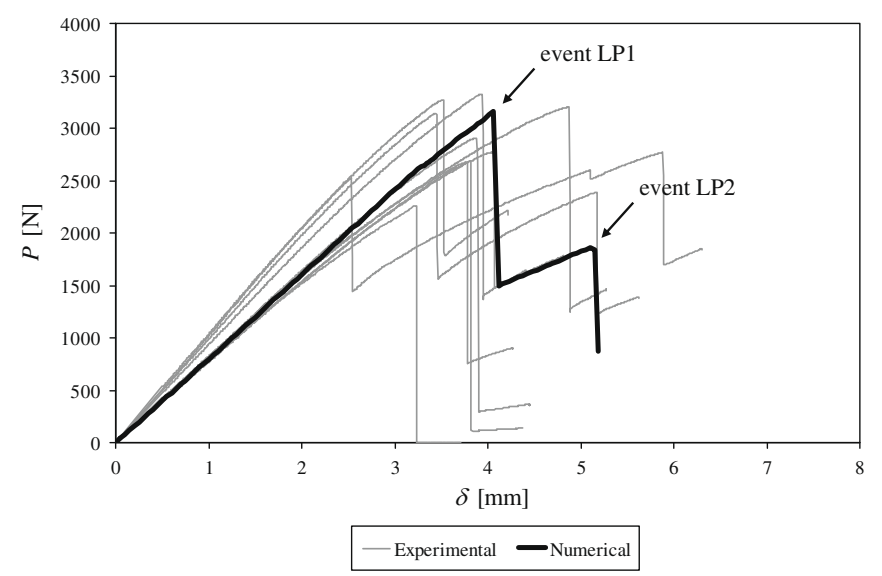

Fig. 10. Experimental and numerical $P-\delta$ curves for the $L_{P}=40 \mathrm{~mm}$ repair.

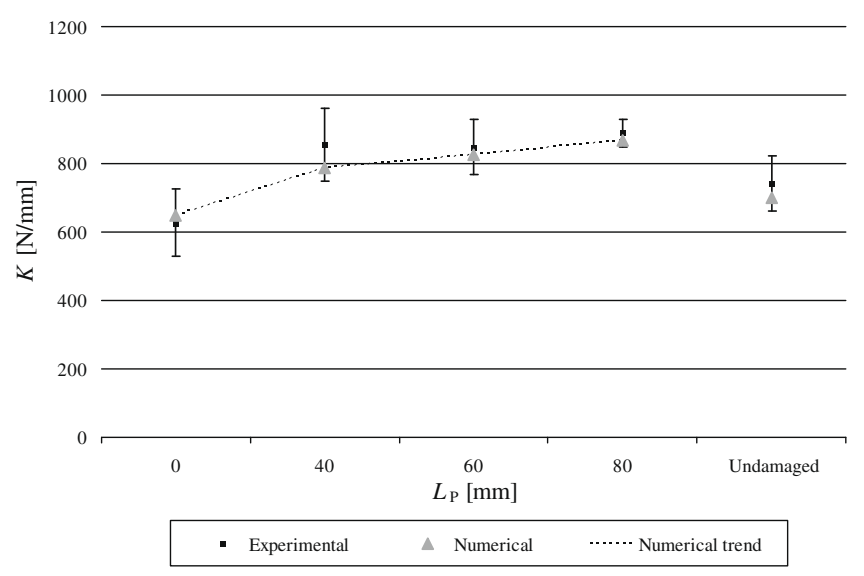

Fig. 11. $K$ as a function of $L_{P}$. Experimental results, numerical predictions and respective tendency as a function of $L_{P}$.

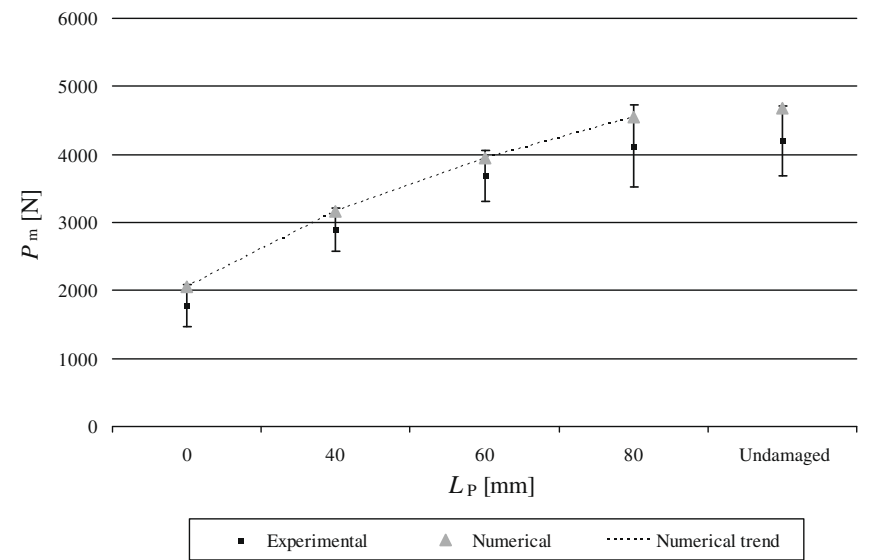

Fig. 12. $P_{m}$ as a function of $L_{P}$. Experimental results, numerical predictions and respective tendency as a function of $L_{P}$.

$L_{P}\left(L_{P}=0 \mathrm{~mm}\right.$ corresponds to the unrepaired beam). $K$ is defined as the $P / \delta$ quotient in the initial part of the $P-\delta$ curve. The FE predictions of $K$ were in close agreement with the tests, although in most cases the average experimental values of $K$ were slightly underpredicted. The increasing tendency of $K$ with $L_{P}$ can be explained by the corresponding increase of the adhesive shear area [19]. The correlations between the experimental and the FE values of $P_{m}$ were also accurate The cross-graining crack led to a drop on $P_{m}$ of slightly more than $50 \%$. Repairing resulted on an approximately proportional increase of $P_{m}$ with $L_{P}$, although at a decreasing rate. Given that in these repairs $P_{m}$ is governed by wood failure at path $\mathrm{A} 1$, it can be concluded that the increasing magnitude of $\sigma$ and $\tau$ peak stresses with $L_{P}$ at the patch edge at $x / L_{P}=1$ is responsible for this non-proportional behaviour with $L_{P}$. Figs. 5 and 6 , although not relating to stresses within the wood, exemplify this tendency. The $L_{P}=80 \mathrm{~mm}$ repair allows the re-establishment of the undamaged beam strength. The slightly smaller FE value of $P_{m}$ justifies the numerical failure at the repaired region (Fig. 7d), rather than vertically below the loading cylinders. However, immediately before fracture, this failure mechanism was imminent, and would occur if $P_{m}$ reached the undamaged beam value (which failed vertically below the loading cylinders).

\section{Concluding remarks}

A repair technique for wood beams of the Pinus Pinaster species damaged by cross-graining was evaluated experimentally and 
numerically under four-point bending. The repair procedure consisted on adhesively-bonding a carbon-epoxy patch at the weakened region considering three patch lengths. In this work, a numerical technique was employed to simulate these repairs, including the possibility of cohesive fracture of the adhesive layer, failure within the wood beam in different planes, and patch interlaminar failure. Cohesive zone modelling was employed to model these fractures, whose properties were obtained either by an inverse method or from literature data. Concerning the failure modes, even though several failure paths were introduced in the numerical models, these managed to reproduce the experimental failure mode accurately for all the conditions tested. These results, together with the accurate failure load predictions, validate the methodology proposed, opening a good perspective for the reduction of costs due to extensive experimentation. This technique can be easily applicable as well to different repair geometries or materials, given that the respective cohesive properties are previously characterized. Design principles were also proposed to execute repairs on wood members damaged by cross-graining, which should not be separated from the specific set of conditions selected for the analysis.

\section{Acknowledgements}

The authors would like to thank the Portuguese Foundation for Science and Technology for supporting the work presented here, through the individual Grant SFRH/BD/30305/2006 and the research Project PDTC/EME-PME/64839/2006.

\section{References}

[1] Akbiyik A. Feasibility investigation into shear repair of timber bridge stringers M.Sc. Thesis, Department of Civil and Environmental Engineering, Graduate School of Tulane University, United States; 2005.

[2] Radford DW, Van Goethem D, Gutkowski RM, Peterson ML. Composite repair of timber structures. Construct Build Mater 2002;16:417-25.

[3] Premrov M, Dobrila P, Bedenik BS. Analysis of timber-framed walls coated with CFRP strips strengthened fibre-plaster boards. Int J Solids Struct 2004:41:7035-48.

[4] Premrov M, Dobrila P, Bedenik BS. Approximate analytical solutions for diagonal reinforced timber-framed walls with fibre-plaster coating material. Construct Build Mater 2004;18:727-35.

[5] Borri A, Corradi M, Grazini A. A method for flexural reinforcement of old wood beams with CFRP materials. Compos: Part B - Eng 2005;36:143-53.

[6] Akbiyik A, Lamanna AJ, Hale WM. Feasibility investigation of the shear repair of timber stringers with horizontal splits. Construct Build Mater 2007;21:991-1000.

[7] Corradi M, Borri A. Fir and chestnut timber beams reinforced with GFRP pultruded elements. Compos: Part B - Eng 2007;38:172-81.

[8] Triantafillou TC. Strengthening of structures with advanced FRPs. Prog Struct Mater Eng 1998;1:126-34.

[9] Humphreys MF, Francey KL. An investigation into the rehabilitation of timber structures with fibre composite materials. In: Proceedings of developments in mechanics of structures and materials conference, Perth, Western Australia, December 2004. p. 1317-22.

[10] Meier U, Winistorfer A. Retrofitring of structures through external bonding of CFRP sheets. In: Proceedings of the 2nd international RILEM symposium. Ghent, Belgium, 23-25 August 1995.

[11] Triantafillou TC. Shear reinforcement of wood using FRP materials. J Mater Civ Eng 1997:9:65-9.

[12] Qiao P, Davalos JF, Zipfel M. Modeling and optimal design of compositereinforced wood railroad crosstie. Compos Struct 1998;41:87-96.

[13] Gentile C, Svecova D, Saltzberg W, Rizkalla SH. Flexural strengthening of timber beams using GFRP. In: Proceedings of the 3rd international conference in advanced composites materials in bridge and structures, Ottawa, Canada, August 15-18, 2000

[14] Johns KC, Lacroix S. Composite reinforcement of timber in bending. Can J Civ Eng 2000;27:899-906.

[15] Svecova D, Eden RJ. Flexural and shear strengthening of timber beams using glass fiber reinforced polymer bars - an experimental investigation. Can J Eng 2004;31:45-55.

[16] Jones R. Upgrading of timber members in historic buildings. J Inst Wood Sci 1997:14:192-203.

[17] Ogawa H. Architectural application of carbon fibers - development of new carbon fiber reinforced glulam. Carbon 2000;38:211-26.

[18] Triantafillou TC. Composites: a new possibility for the shear strengthening of concrete, masonry and wood. Compos Sci Technol 1998;58:1285-95.

[19] Lopez-Anido R, Michael AP, Sandford TC. Experimental characterization of FRP composite-wood pile structural response by bending tests. Mar Struct 2003;16:257-74.

[20] Lopez-Anido R, Michael AP, Sandford TC, Goodell B. Repair of wood piles using prefabricated fiber-reinforced polymer composite shells. J Perform Construct Fac 2005;19:78-87.

[21] Lionetto F, Frigione M. Mechanical and natural durability properties of wood treated with a novel organic preservative/consolidant product. Mater Des 2009;30:3303-7.

[22] Zandbergs JG, Smith FW. Finite element fracture prediction for wood with knots and cross grain. Wood Fiber Sci 1988;20:97-106.

[23] Winandy JE. Wood properties. Encyclopedia of agricultural science, vol. 4. Orlando, USA: Academic Press; 1994

[24] de Lorenzis L, Scialpi V, Tegola AL. Analytical and experimental study on bonded-in CFRP bars in glulam timber. Compos: Part B - Eng 2005;36:279-89.

[25] Andersson T, Stigh U. The stress-elongation relation for an adhesive layer loaded in peel using equilibrium of energetic forces. Int J Solids Struct 2004;41:413-34

[26] Hogberg JL, Stigh U. Specimen proposals for mixed mode testing of adhesive layer. Eng Fract Mech 2006;73:2541-56.

[27] Leffler K, Alfredsson KS, Stigh U. Shear behaviour of adhesive layers. Int J Solids Struct 2007;44:530-45.

[28] Campilho RDSG, de Moura MFSF, Ramantani DA, Morais JJL, Domingues JJMS. Tensile behaviour of three-dimensional carbon-epoxy adhesively-bonded single and double-strap repairs. Int J Adhes Adhes 2009;29:678-86.

[29] Marques EAS, da Silva LFM. Joint strength optimization of adhesively bonded patches. J Adhes 2008;84:917-36.

[30] de Moura MFSF, Gonçalves JPM, Chousal JAG, Campilho RDSG. Cohesive and continuum mixed-mode damage models applied to the simulation of the mechanical behaviour of bonded joints. Int J Adhes Adhes 2008;28:419-26.

[31] de Moura MFSF, Campilho RDSG, Gonçalves JPM. Crack equivalent concept applied to the fracture characterization of bonded joints under pure mode I loading. Compos Sci Technol 2008;68:2224-30.

[32] de Moura MFSF, Campilho RDSG, Gonçalves JPM. Pure mode II fracture characterization of composite bonded joints. Int $\mathrm{J}$ Solids Struct 2009;46:1589-95.

[33] Silva MAL. Estudo das propriedades de fractura em modo II e em modo III da madeira de pinus pinaster ait. M.Sc. Thesis, Department of Mechanical Engineering and Industrial Management, Engineering Faculty of Porto University, Porto, Portugal; 2005.

[34] Silva MAL, Morais JJL, de Moura MFSF, Lousada JL. Mode II wood fracture characterization using the ELS test. Eng Fract Mech 2007;74:2133-47.

[35] Campilho RDSG, de Moura MFSF, Pinto AMG, Morais JJL, Domingues JJMS, Modelling the tensile fracture behaviour of CFRP scarf repairs. Compos: Part B - Eng 2009;40:149-57.

[36] Lee J, Soutis C. Measuring the notched compressive strength of composite laminates: specimen size effects. Compos Sci Technol 2008;68:2359-66.

[37] Ikeda T, Yamashita A, Lee D, Miyazaki N. Failure of a ductile adhesive layer constrained by hard adherends. J Eng Mater Technol 2000;122:80-5.

[38] Bakis CE, Bank LC, Brown VL, Cosenza E, Davalos JF, Lesko JJ, et al. Fiberreinforced polymer composites for construction - state-of-the-art review. J Compos Construct 2002;6:73-87.

[39] Campilho RDSG, de Moura MFSF, Domingues JJMS. Modelling single and double-lap repairs on composite materials. Compos Sci Technol 2005;65:1948-58.

[40] Campilho RDSG, de Moura MFSF, Domingues JJMS. Stress and failure analyses of scarf repaired CFRP laminates using a cohesive damage model. J Adhes Sci Technol 2007;21:855-970.

[41] Campilho RDSG, de Moura MFSF, Domingues JJMS, Morais JJL. Computational modelling of the residual strength of repaired composite laminates using a cohesive damage model. J Adhes Sci Technol 2008;22:1565-91. 